\title{
STUDI INTERSEPSI BERBAGAI KELAS UMUR KELAPA SAWIT
}

\author{
Muhammad Ikhsan ${ }^{1}$, Meidia Refiyanni ${ }^{2}$, dan Imun Safiana ${ }^{3}$ \\ ${ }^{1,2}$ Dosen Jurusan Teknik Sipil, Fakultas Teknik, Universitas Universitas Teuku Umar, Meulaboh \\ ${ }^{3}$ Jurusan Teknik Sipil, Fakultas Teknik, Universitas Universitas Teuku Umar, Meulaboh \\ Email: mikhsanrustam@gmail.com
}

\begin{abstract}
Abstrak
Seiring dengan Meningkatnya permintaan akan bahan baku untuk pembuatan minyak dari kelapa sawit (palm oil) maka pembukaan lahan untuk perkebunan juga semakin besar, akibatnya tutupan lahan menjadi berpengaruh terhadap jumlah air yang diresap oleh tanah karena terjadinya intersepsi. Intersepsi hujan oleh tanaman adalah proses tertahannya air hujan pada permukaan tanaman yang kemudian diuapkan kembali ke atmosfer atau diserap oleh tanaman yang bersangkutan. Air hujan yang jatuh diatas tanaman tidak langsung sampai ke permukaan tanah untuk berubah menjadi aliran permukaan (surface run off), tetapi untuk sementara air hujan akan ditampung oleh tajuk, batang dan tanaman. Setelah tempattempat tersebut jenuh air, air hujan akan sampai ke permukaan tanah melalui air lolos (throughfall) dan aliran batang (stemflow). Dalam analisis keseimbangan air, intersepsi diperlakukan sebagai kehilangan air (rainfall interception loss) jenis tanaman yang digunakan pada penelitian ini adalah tanaman kelapa sawit. Hal ini disebabkan karena daerah sekitar banyak terdapat perkebunan kelapa sawit. Tujuan studi ini adalah mengetahui besarnya intersepsi kelapa sawit dari berbagai kelas umur. Penelitian dilakukan secara langsung di lapangan pada perkebunan kelapa sawit yang terletak di PT. Scofindo Nagan Raya. Untuk mengetahui besarnya nilai intersepsi air hujan dapat dilakukan melalui pendekatan neraca volume yaitu dengan mengukur curah hujan, air lolos dan aliran batang. Hasil penelitian akan didapatkan hubungan antara curah hujan dengan intersepsi hujan berbeda pada tiap kelas umur. Luas proyeksi tajuk dan curah hujan berpengaruh terhadap intersepsi, air lolos dan aliran batang. Hubungan ini akan membentuk persamaan regresi yang akan digunakan dalam menghitung besarnya intersepsi hujan oleh perkebunan kelapa sawit. Hasil perhitungan didapatkan intersepsi yang terjadi pada pohon kelapa sawit yang 10 tahun adalah sebesar 40,81\% $\mathrm{mm}$ dan yang 20 tahun adalah 64,04\% dari total curah hujan sebesar 225,00 mm. Perhitungan air lolos yang 10 tahun sebesar 56,62 \% dan yang 20 tahun sebesar 36,25\%. Perhitungan aliran batang yang 10 tahun adalah 7,17\% dan yang 20 tahun sebesar 3,12\%. Semakin besar curah hujan maka intersepsi semakin besar, dan semakin tua umur kelapa sawit maka intersepsi juga semakin besar.
\end{abstract}

Kata Kunci: Tanaman Kelapa sawit, intersepsi, air lolos, aliran batang

\section{Abstract}

Along with the increasing demand for raw materials for the manufacture of palm oil, the clearing of land for plantations are also getting bigger, land cover becomes consequently affect the amount of water absorbed by the soil due to the interceptionrainfall interception by plants is the retention of rain water on the surface of the plant which is then evaporated back into the atmosphere or absorbed by the plant in question. Rainwater that falls on top of the plant is not directly to the surface of the soil to surface run-off, but for a while rainwater will be collected by a canopy, trunk and plants. After these places saturated with water, rain water will get to the ground level throughfall stemflow. In the water balance analysis, interception treated as rainfall interception loss type of plants used in this study is a plant oil palm. This is because the area around there are many oil palm plantations. Purpose of this study was to determine the amount of palm oil interception of various age classes. Research carried out directly on the ground in oil palm plantations are located in PT. Scofindo Nagan Raya. To determine the value of the interception of rainwater can be done through a balance sheet approach is to measure the volume of rainfall, water escapes and stem flow. The research results will be obtained relationship between rainfall and interception of rain is different in each age class. Wide canopy projection and influence the interception of rainfall, water escapes and stem flow. This relationship will form the regression equation to be used in calculating the amount of rainfall interception by oil palm plantations. Calculation 
resulting interception occurred in the oil palm trees are 10 years of $40.81 \% \mathrm{~mm}$ and 20 years is $64.04 \%$ of the total rainfall of $225.00 \mathrm{~mm}$. Calculation of throughfall that 10 years of $56.62 \%$ and the 20-year amounted to $36.25 \%$. stemflow of the 10-year was $7.17 \%$ and the 20-year at $3.12 \%$. The greater the rainfall, the greater the interception, and the older the palm, the interception is also getting bigger.

\section{Key Words : Plant oil palm, Interception, Troughfall, Steamflow}

\section{PENDAHULUAN}

Kondisi hutan bila dilihat dari luasan penutupan lahan/vegetasi telah mengalami perubahan yang cepat, sesuai perkembangan pembangunan dan perjalanan waktu. Beberapa faktor yang mengakibatkan perubahan tersebut antara lain pertambahan penduduk, dan pembangunan diluar sektor kehutanan yang sangat pesat. Kedua faktor tersebut memberikan pengaruh besar terhadap meningkatnya kebutuhan akan lahan dan produk-produk dari hutan. Kondisi demikian diperparah adanya perambahan hutan dan terjadinya kebakaran hutan yang mengakibatkan semakin luasnya kerusakan hutan di indonesia. Intersepsi merupakan faktor penting dalam daur hidrologi karena dengan adanya proses intersepsi, berkurangnya air hujan yang sampai di permukaan tanah adalah cukup besar.

Ward dan Robinson (1990) menyatakan tentang kehilangan Air oleh proses intersepsi merupakan bentuk kehilangan air yang nyata dalam sistem neraca air suatu DAS. Hasil penelitian Bruijnzeel (1990), diperoleh besarnya intersepsi hujan berkisar 35-75\% dari keseluruhan evapotranspirasi di atas tegakan hutan, sementara besarnya intersepsi di hutan hujan tropis berkisar antara 10-35\% dari curah hujan total. Hasil penelitian Benara (2011), diperoleh besarnya nilai intersepsi tanaman Lamtoro adalah sebesar 70,27\% dari curah hujan total dan besarnya nilai intersepsi tanaman Kopi Arabika adalah sebesar $62,33 \%$ dari curah hujan total.

Proses intersepsi air hujan oleh tanaman dapat memberikan dampak terhadap hasil air pada suatu DAS dengan skala bervariasi tergantung pada jenis tanaman dan jarak tanamnya. Dalam menentukan besarnya intersepsi dan curah hujan pada setiap kejadian hujan pada suatu DAS, diperlukan model empiris dari hasil penelitian lapangan untuk setiap jenis tanaman. Salah satu Jenis tanaman yang digunakan dalam penelitian ini adalah Kelapa Sawit. Hal ini disebabkan karena salah satu produk unggulan/andalan Kabupaten Nagan Raya yaitu komoditi kelapa sawit. Penelitian ini dilakukan secara langsung di lapangan yaitu pada perusahaan perkebunan Kelapa Sawit di PT. Scofindo yang terletak di Desa Jati Rejo, Kecamatan Kuala Pesisir, Kabupaten Nagan Raya. Penelitian ini tentang intersepsi berbagai kelas umur kelapa sawit dilakukan pada umur sawit 10 dan 20 tahun.

Hasil penelitian ini menunjukkan bahwa tanaman kelapa sawit memiliki kemampuan mengintersepsi yang 10 tahun adalah sebesar 40,81\% dan yang 20 tahun sebesar 64,04\% dari total curah hujan sebesar 225,00 mm. Air lolos pada umur 10 tahun adalah 59,40\% dan yang umur 20 tahun adalah 36,53\% dari total hari hujan sebesar $225,00 \mathrm{~mm}$. Aliran batang pada umur 10 tahun adalah $6,17 \%$ dan pada umur 20 tahun adalah 3,12\% dari total hari hujan sebesar 225,00 mm. Manfaat studi ini diharapkan adanya informasi tentang pengaruh intersepsi hujan pada perkebunan kelapa sawit PT. Scofindo, Desa Jati Rejo,

Kecamatan Kuala $\quad$ Pesisir, $\quad$ Kabupaten Nagan




\section{Hujan dan Intersepsi Hujan}

Hujan adalah endapan air di udara yang jatuh permukaan bumi, hujan berasal dari uap air di atmosfer, sehingga bentuk dan jumlahnya dipengaruhi oleh faktor klimatologi seperti angin, temperatur dan tekanan atmosfer. Uap air tersebut akan naik ke atmosfer sehingga mendingin dan terjadi kondensasi menjadi butir-butir air dan kristal-kristal es yang akhirnya jatuh sebagai hujan (Triatmodjo, 2009 : 17). Intersepsi air hujan (rainfall interception loss) adalah proses ketika air hujan jatuh pada permukaan vegetasi, tertahan beberapa saat, kemudian diuapkan kembali (hilang) ke atmosfer atau diserap oleh vegetasi yang bersangkutan. Air hujan jatuh pada permukaan tajuk vegetasi akan mencapai permukaan tanah melalui dua proses mekanis, yaitu air lolos (thoughfall) dan aliran batang (stemflow). Proses intersepsi terjadi selama berlangsungnya curah hujan dan setelah hujan berhenti sampai ke permukaan tajuk vegetasi menjadi kering kembali, setiap kali hujan jatuh didaerah vegetasi, ada sebagian air yang tak pernah mencapai permukaan tanah dan dengan demikian tidak berperan dalam membentuk kelembapan tanah, air larian atau air intersepsi tajuk, serasah dan tumbuhan bawah (Asdak, 2010).

\section{Analisis intersepsi Hujan}

Dari hasil pengukuran curah hujan, troughfall dan stemflow kemudian dihitung besarnya intersepsi berdasarkan pendekatan neraca volume. persamaan untuk menentukan besarnya intersepsi pada tanaman pohon-pohonan yang terjadi pada suatu plot percobaan. Persamaan tersebut dirumuskan sebagai berikut: (Asdak, 2010) :

$$
\mathrm{I}=P_{g-}(\mathrm{Tf}+\mathrm{Sf})
$$

\section{Analisis data curah hujan}

Analisis data curah hujan yaitu data mengukur besarnya curah hujan yang tidak tertahan oleh tanaman. Curah hujan harian atau mingguan adalah komponen pertama yang harus diperoleh dengan alat pengukur hujan di tempat yang terbuka tanpa ada halangan dari tanaman (Asdak 2010). Dari hasil pengukuran awal di lapangan besarnya nilai curah hujan) dan akan dikonversikan kedalam satuan milimeter ( $\mathrm{mm}$ ). Persamaan yang digunakan dalam mengkonversi adalah sebagai berikut:

$$
P_{g}=\frac{V}{A_{\text {alat }}}
$$

\section{Analisis data air lolos (throughfall)}

Air lolos (throughfall) adalah air hujan jatuh langsung ke permukaan tanah melalui ruang antar tajuk/daun atau menetes melalui daun, batang dan cabang (Asdak, 2010). Dari hasil pengukuran awal di lapangan besarnya nilai throughfall didapatkan dalam satuan mililiter (ml) dan akan dikonversikan ke dalam satuan milimeter (mm). Persamaan yang digunakan dalam mengkonversi adalah sebagai berikut:

$$
\lambda=\frac{\mathrm{A}_{\text {tajuk }}}{\mathrm{A}_{\text {platik }}}
$$




$$
T_{f}=\lambda \frac{T_{f}^{\prime}}{A_{\text {plastik }}}
$$

\section{Analisis data aliran batang (stemflow)}

Aliran batang (stemflow) adalah air hujan yang dalam perjalanan mencapai permukaan tanah mengalir batang vegetasi (Asdak, 2010). Dari hasil pengukuran awal di lapangan besarnya nilai stemflow didapatkan dalam satuan mililiter (ml) dan akan dikonversikan kedalam satuan milimeter (mm). Persamaan yang digunakan dalam mengkonversi adalah sebagai berikut

$$
S_{f}=\frac{S^{\prime}}{A_{t a j u k}}
$$

\section{METODOLOGI PENELITIAN}

\section{Pengumpulan Data}

Untuk mendapatkan data primer dilakukan pengamatan secara langsung dilapangan selama tiga bulan untuk mengetahui nilai intersepsi pada tanaman kelapa sawit. Tanaman kelapa sawit yang dijadikan objek pada studi ini berumur 10 dan 20 tahun. Penelitian dilakukan selama 25 hari dan data curah hujan yang diperoleh bervariasi.

\section{Pengadaan Bahan dan Alat}

Pada penelitian ini objek yang diteliti adalah tanaman kelapa sawit. Peralatan yang digunakan dalam penelitian ini adalah sebagai berikut :

1. Alat penakar curah hujan

2. Terpal

3. Penampung Aliran Batang

4. Gelas ukur

5. Kayu

6. Lem silicon

7. Selang

8. Jerigen

9. Pipa

\section{Prosedur Penelitian}

Penelitian ini dilakukan pada perkebunan kelapa sawit yang terletak didesa Jati Rejo, Kecamatan Kuala Pesisir, Kabupaten Nagan Raya. Pekerjaan penelitian meliputi pengadaan bahan dan pengukuran intersepsi.

\section{Pemasangan alat}

a. Alat penakar curah hujan 
Alat curah hujan dipasang setinggi $120 \mathrm{~cm}$ dari permukaan tanah yang terletak disekitar lokasi penelitian pada lahan terbuka. Alat penakar curah hujan dari tipe observatorium dengan luas penampang permukaan adalah $100 \mathrm{~cm}^{2}$, untuk mengetahui pengambilan data curah hujan maka dipakai gelas ukur.

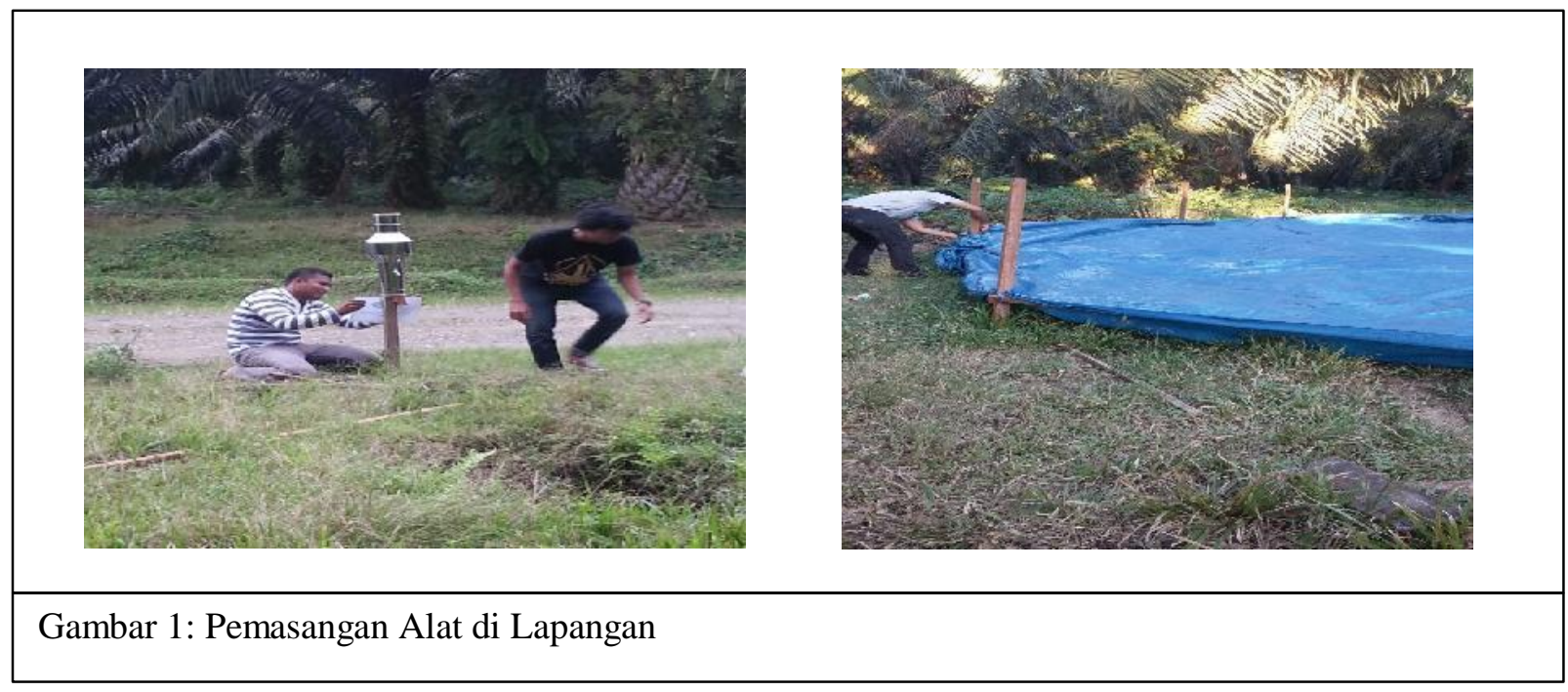

\section{b. Air lolos (throughfall)}

Pemasangan alat untuk Air lolos menggunakan plastik yang dibentangkan di bawah kanopi tanaman. Plastik yang terbentang memiliki elevasi, sehingga memiliki kemiringan. Pada ujung plastik yang memiliki elevasi terendah diletakkan selang yang dihubungkan dengan jerigen untuk menampung air yang jatuh.

\section{c. Aliran Batang (stemflow)}

Pemasangan alat aliran batang menggunakan lempeng seng, yang dipasang melingkar pada batang tanaman. Lempeng dipasang dari permukaan tanah yang pada salah satu sisinya dibuat saluran agar dapat mengalirkan air yang tertampung ke dalam jerigen.

\section{Pengamatan dan Pengukuran}

Pengamatan dan pengukuran dilaksanakan dalam penelitian ini terdiri dari:

a. Pencatatan curah hujan setiap hari hujan pada pukul 07.30 WIB dan dihitung sebagai hari hujan yang dicatat selama 25 hari.

b. Pencatatan air lolos (throughfall) pada pohon kelapa sawit dilakukan setiap hari hujan pada pukul 07.30 WIB dan dhitung sebagai hari hujan sebelumnya. Jumlah hari hujan yang dcatat selama 25 hari.

c. Pencatatan air aliran batang (stemflow) pada pohon kelapa sawit dilakukan setiap hari hujan pada pukul 07.30 WIB dan dihitung sebagai hari hujan sebelumnya. Jumlah hari hujan yang dicatat selama 25 hari.

\section{Analisis Data Penelitian}

Analisis data penelitian dilakukan untuk menentukan nilai intersepsi hujan pada perkebunan Kelapa Sawit yang telah diukur dilapangan. Analisis data penelitian yang dilakukan adalah sebagai berikut:

Analisis Perhitungan intersepsi hujan

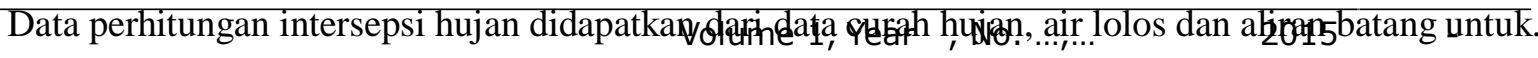


Perhitungan intersepsi hujan (I) dapat dihitung dengan persamaan 2.1.

Analisis data curah hujan

Data curah hujan didapat dilapangan dengan cara memasang penakar curah hujan diruang terbuka untuk mengetahui pengambilan data maka dipakai gelas ukur. Perhitungan analisa data curah hujan (pg) dapat dihitung dengan persamaan 2.2.

Analisis data air lolos

Data air lolos didapat dilapangan dengan menggunakan plastik yang dibentangkan di bawah kanopi tanaman. Plastik yang terbentang memiliki elevasi, sehingga memiliki kemiringan. Pada ujung plastik yang memiliki elevasi terendah diletakkan selang yang dihubungkan dengan jerigen untuk menampung air yang jatuh. Perhitungan data air lolos dapat dihitung dengan persamaan 2.3 sampai 2.4.

Analisis aliran batang

Data aliran batang didapatkan dilapangan dengan memggunakan lempeng seng yang melingkar pada batang tanaman Lempeng dipasang dari permukaan tanah yang pada salah satu sisinya dibuat saluran agar dapat mengalirkan air yang tertampung ke dalam jerigen. Perhitungan analisa aliran batang ( $\mathrm{Sf}$ ) dapat dihitung dengan persamaan 2.5 .

\section{HASIL DAN PEMBAHASAN}

Hasil penelitian intersepsi hujan pada perkebunan kelapa sawit menunjukkan bahwa nilai intersepsi pada pohon kelapa sawit cukup besar, Penelitian ini dilakukan selama lebih dari 3 (tiga) bulan mulai dari tanggal 5 Januari 2015 sampai dengan 12 April 2015 (dengan 25 kali hari hujan) pada perkebunan kelapa sawit yang terletak di PT. Hasil pengukuran dan perhitungan intersepsi hujan, air lolos, aliran batang dan curah hujan pada tanaman kelapa sawit dapat dilihat pada Tabel 1 berikut ini:

Tabel 1. Hasil pengukuran dan perhitungan intersepsi hujan, air lolos, aliran batang dan curah hujan pada tanaman kelapa sawit

\begin{tabular}{|c|c|c|c|c|c|c|c|c|}
\hline \multirow{2}{*}{$\begin{array}{c}\text { Umur Kelapa } \\
\text { Sawit }\end{array}$} & \multirow{2}{*}{ Hari Hujan } & \multirow{2}{*}{$\begin{array}{c}\text { Jumlah } \\
\text { Curah Hujan } \\
\text { (mm) }\end{array}$} & \multicolumn{2}{|c|}{$\begin{array}{c}\text { Air Lolos } \\
\text { (throughfall) }\end{array}$} & \multicolumn{2}{|c|}{$\begin{array}{c}\text { Aliran Batang } \\
\text { (stemflow) }\end{array}$} & \multicolumn{2}{|c|}{ Intersepsi } \\
\hline & & & Mm & $\%$ & $\mathrm{Mm}$ & $\%$ & $\mathrm{~mm}$ & $\%$ \\
\hline 10 Tahun & 25 & 225.00 & $\begin{array}{c}127 . \\
41\end{array}$ & $\begin{array}{l}59 . \\
40\end{array}$ & $\begin{array}{l}16 . \\
12\end{array}$ & $\begin{array}{l}6 . \\
17\end{array}$ & $\begin{array}{c}91.8 \\
2\end{array}$ & $\begin{array}{l}40 . \\
81\end{array}$ \\
\hline 20 Tahun & 25 & 225.00 & $\begin{array}{c}81.5 \\
7\end{array}$ & $\begin{array}{l}36 . \\
53\end{array}$ & $\begin{array}{c}7.0 \\
2\end{array}$ & $\begin{array}{l}3 . \\
12\end{array}$ & $\begin{array}{c}144 . \\
09\end{array}$ & $\begin{array}{l}64 . \\
04\end{array}$ \\
\hline
\end{tabular}

Menunjukkan bahwa nilai intersepsi hujan terjadi pada umur sawit 10 tahun yaitu sebesar $91.82 \mathrm{~mm}$, sedangkan nilai intersepsi hujan pada umur 20 tahun yaitu sebesar $144.09 \mathrm{~mm}$. Grafik hasil pengukuran dan perhitungan intersepsi hujan pada tanaman kelapa sawit umur 10 an 20 tahun dapat dilihat pada gambar 3 . 


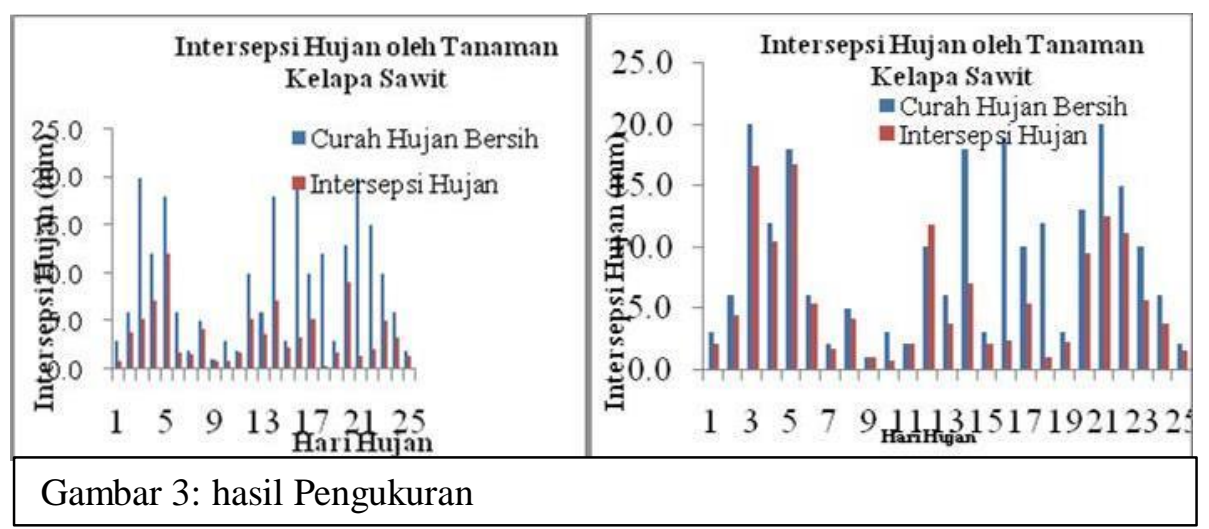

Dari gambar di atas menunjukkan bahwa nilai intersepsi hujan (I) tertinggi pada umur 10 tahun terjadi pada hari hujan ke-5 yaitu sebesar 12,132 mm, sedangkan nilai intersepsi hujan (I) terendah terjadi pada hari hujan ke-18 yaitu sebesar 0,345 mm. Nilai intersepsi didapatkan dari data curah maksimum harian yang berasal dari pengolahan data curah hujan dilapangan.

Dari gambar di atas menunjukkan bahwa nilai intersepsi hujan tertinggi pada umur 20 tahun terjadi pada hari hujan ke-5 yaitu sebesar $16,779 \mathrm{~mm}$, sedangkan nilai intersepsi hujan terendah terjadi pada hari hujan ke-10 yaitu sebesar $0,699 \mathrm{~mm}$. Nilai intersepsi didapatkan dari data curah maksimum harian yang berasal dari pengolahan data curah hujan dilapangan. Berdasarkan grafik di atas intersepsi tertinggi 20 tahun lebih besar dibandingkan dengan yang 10 tahun.

\section{Hubungan Intersepsi dengan Curah Hujan}

Intersepsi memiliki hubungan yang sangat erat dengan curah hujan. Semakin tinggi curah hujan maka semakin tinggi pula air yang akan terintersep. Pada curah hujan yang kecil, ada kemungkinan seluruh curah hujan akan tertahan oleh tajuk kemudian menyebabkan nilai intersepsinya tinggi. Umumnya hubungan antara intersepsi dengan curah hujan mengikuti model regresi linear. Hubungan curah hujan dengan intersepsi pada tanaman kelapa sawit dapat di lihat pada Gambar 4.

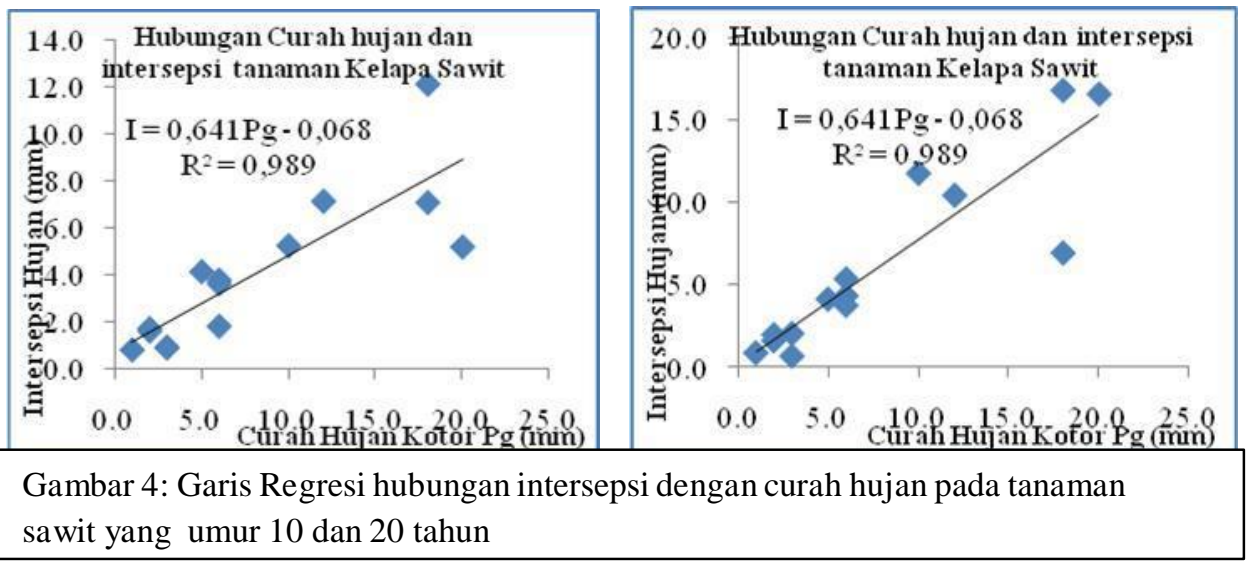

Garis regresi di atas menunjukkan bahwa curah hujan dan intersepsi memiliki hubungan yang positif, dimana ketika curah hujan meningkat maka nilai intersepsi akan semakin meningkat, namun peningkatan terjadi tidak secara drastis. Dari grafik diatas menunjukkan bahwa semakin tua umur kelapa sawit maka intersepsi curah hujan semakin tinggi. 


\section{Hasil dan Pembahasan Air Lolos}

Air lolos mempunyai potensi atau peluang yang lebih besar untuk mencapai permukaan tanah. Air lolos terjadi ketika curah hujan yang terjadi lebih besar dari pada kapasitas penyimpanan tajuk sehingga tajuk mengalami kejenuhan dalam menampung air hujan. Hasil pengukuran air lolos pada umur 10 selama periode penelitian sebesar $127.41 \mathrm{~mm}$ atau 59,40\% dari total curah hujan. Hasil pengukuraan air lolos pada umur 20 tahun adalah $81,57 \mathrm{~mm}$ atau $36,33 \%$. Hasil pengukuran air lolos yang diperoleh dilapangan air lolos tertinggi pada umur 10 tahun terjadi pada hari ke 21 yaitu sebesar 18,30 dan terkecil pada hari ke 9 yaitu sebesar 0,180. Air lolos didapatkan dari data curah maksimum harian yang berasal dari pengolahan data curah hujan dilapangan. Hasil pengukuran air lolos yang diperoleh dilapangan air lolos pada umur 20 tahun terjadi pada hari ke 16 yaitu sebesar 16,26 dan terkecil pada hari ke 9 yaitu sebesar 0,000. Air lolos didapatkan dari data curah maksimum harian yang berasal dari pengolahan data curah hujan dilapangan.

\section{Hubungan Air Lolos dengan Curah Hujan}

Curah hujan dengan air lolos memiliki hubungan yang sangat erat dimana ketika curah hujan meningkat maka air hujan yang menjadi air lolos juga akan meningkat. Umumnya hubungan antara air lolos dengan curah hujan mengikuti model regresi linear. Hubungan curah hujan dengan air lolos pada tanaman kelapa sawit dapat dilihat pada Gambar 5 berikut ini :

\begin{tabular}{|c|c|}
\hline $\begin{array}{c}\text { Hubungan Curah Hujan dan Air Lolos } \\
\text { Tanaman Kelapa Sawit }\end{array}$ & $\begin{array}{c}\text { Hubungan Curah Hujan dan Air Lolos } \\
\text { pada Tanaman Kelapa Sawit }\end{array}$ \\
\hline 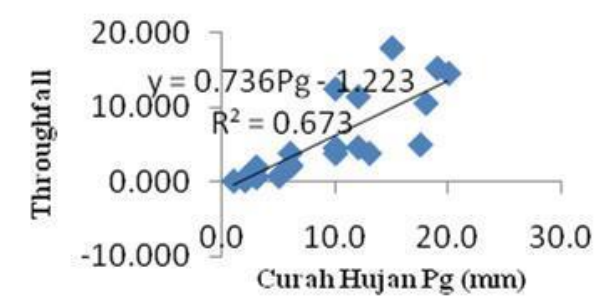 & 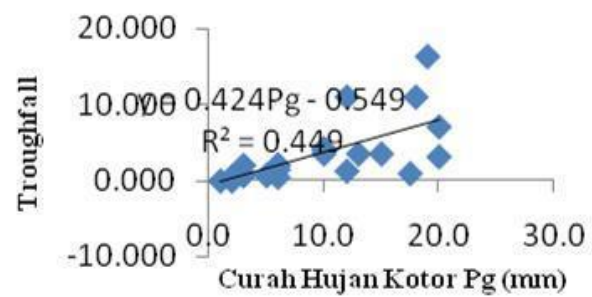 \\
\hline $\begin{array}{c}\text { Grafik 5: Garis Regresi hubungan through } \\
\text { yang umur } 10 \text { dan } 20 \text { tahun }\end{array}$ & gan curah hujan pada tanaman sawit \\
\hline
\end{tabular}

\section{Hasil dan Pembahasan Aliran Batang}

Salah satu faktor yang mempengaruhi besarnya aliran batang adalah struktur batang tersebut. Semakin halus struktur batang pada umumnya aliran batangnya akan semakin tinggi, demikian sebaliknya. Struktur kelapa sawit umur 10 sebesar $16.12 \mathrm{~mm}$ atau $6.17 \%$ dari total curah hujan. Hasil pengukuraan aliran batang pada umur 20 tahun adalah $7.02 \mathrm{~mm}$ atau 3.13\%. perhitungannya dapat dilihat pada gambar 6 . 


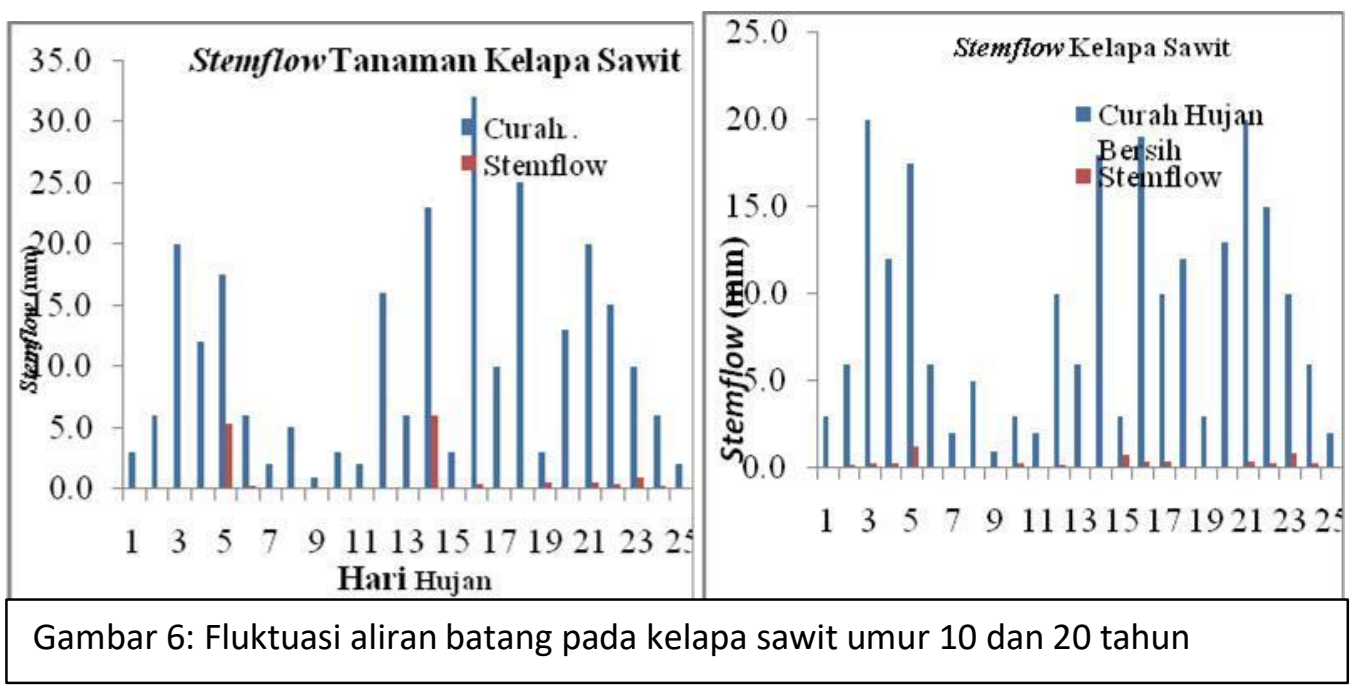

Hasil pengukuran aliran batang yang diperoleh dilapangan aliran batang tertinggi pada umur 10 tahun terjadi pada hari ke 14 yaitu sebesar 6.00 dan terkecil pada hari ke 9 dan 11 yaitu sebesar 0,000. Pada beberapa kali pengukuran diperoleh air hujan yang tidak menjadi aliran batang, hal ini disebabkan karena permukaan batang kelapa sawit yang memiliki pelapah sehingga curah hujan yang terjadi sebagian melekat pada pangkal pelapah tersebut. Aliran batang didapatkan dari data curah maksimum harian yang berasal dari pengolahan data hujan dilapangan. Hasil pengukuran yang diperoleh dilapangan aliran batang tertinggi pada umur 20 tahun terjadi pada hari ke 5 yaitu sebesar 1,220 dan terkecil pada hari ke 11 dimana tidak terjadi aliran batang karena air hujan yang jatuh tidak menjadi aliran batang. Aliran batang didapatkan dari data curah maksimum harian yang berasal dari pengolahan data hujan dilapangan. Dari kedua kelas umur, kelapa sawit pada kelas umur 20 tahun lebih rendah disebabkan karena pohon kelapa sawit yang 20 tahun memiliki tajuk yang paling rapat dan percabangan lebih banyak dan tinggi kelapa sawit dibandingkan yang 10 tahun.

\section{Hubungan Aliran Batang dengan Curah Hujan}

Aliran batang dengan curah hujan memiliki hubungan dimana semakin tinggi curah hujan maka semakin besar aliran batang dan semakin tinngi intensitas hujan maka semakin besar persentase aliran batang yang terjadi dan juga dipengaruhi oleh kekasaran batang. Apabila terjadi hujan dengan intensitas rendah dan waktu singkat, maka tidak terjadi aliran batang. Umumnya hubungan antara intersepsi dengan curah hujan mengikuti model regresi linear. Hubungan curah hujan denganaliran batang pada tanaman kelapa sawit dapat dilihat pada

Gambar 7. 


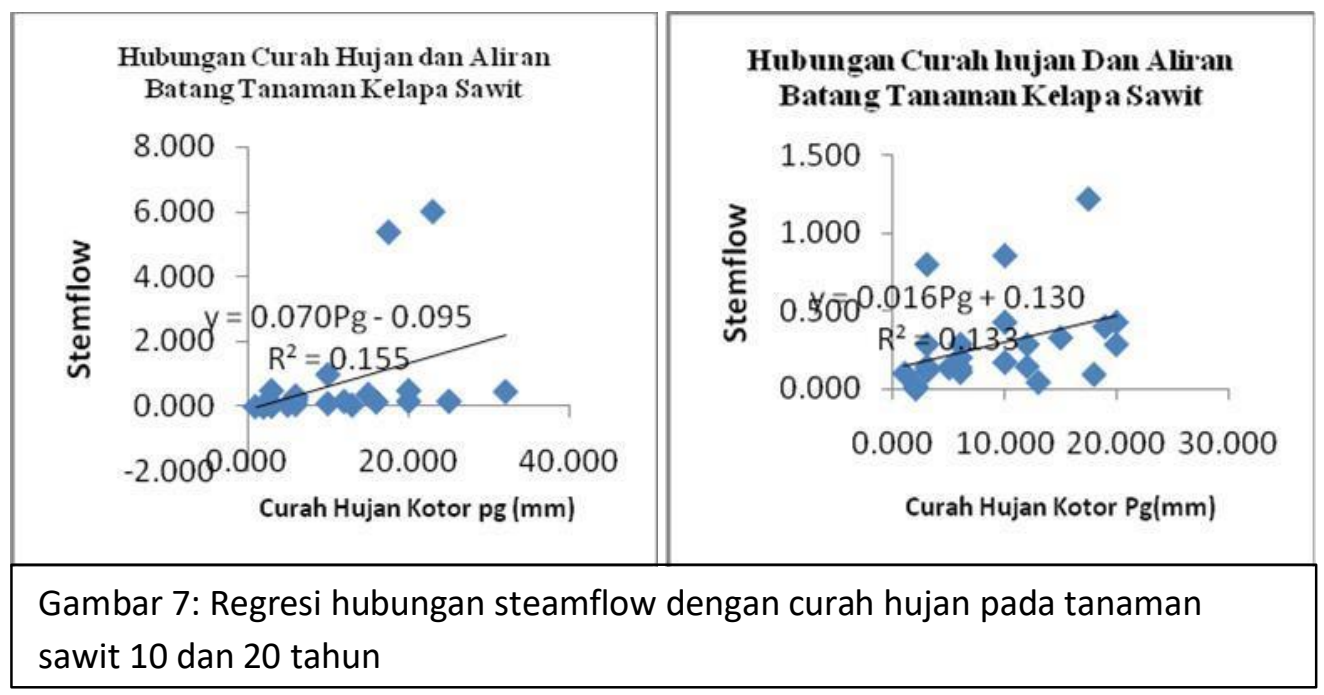

Berdasarkan gambar 7 menunjukkan korelasi yang positif, dimana semakin tinggi curah hujan maka semakin besar aliran batang dan hal ini terjadi secara dratis yang tidak menunjukkan waktu konstan. Grafik linier ini didapatkan dari aliran batang dan curah hujan yang diambil data dilapangan

\section{KESIMPULAN DAN SARAN}

1. Besarnya nilai intersepsi tanaman Kelapa Sawit yang 10 tahun adalah sebesar $40,81 \%$ dari total curah hujan sebesar $225.00 \mathrm{~mm}$ dan intersepsi tanaman kelapa sawit yang 20 tahun adalah $64.04 \%$ dari total curah hujan $225.00 \mathrm{~mm}$.

2. Semakin tinggi curah hujan, maka jumlah air yang diintersepsikan juga semakin besar, pada curah hujan yang turun kecil maka ada kemungkinan seluruh curah hujan yang turun akan diintersepsikan.

3. Hubungan intersepsi dengan curah hujan pada tanaman Kelapa Sawit membentuk persamaan regresi linear yaitu : Tanaman Kelapa Sawit 10 tahun adalah $\mathrm{I}=0,641 \mathrm{Pg}-0,068$ dan $\mathrm{R}^{2}=0,989$ dan yang 20 tahun I= $0,641 \mathrm{Pg}-0,068$ dan $\mathrm{R}^{2}=0,989$. Hubungan air lolos dengan curah hujan pada tanaman Kelapa Sawit membentuk persamaan regresi linear yaitu : Tanaman Kelapa Sawit 10 tahun adalah $\mathrm{Tf}=0,736 \mathrm{Pg}-1,223$ dan $R^{2}=0,673$ dan yang 20 tahun $\mathrm{Tf}=0,424 \mathrm{Pg}-0,549$ dan $\mathrm{R}^{2}=0,449$.

4. Hubungan aliran batang dengan curah hujan pada tanaman Kelapa Sawit membentuk persamaan regresi linear yaitu : Tanaman Kelapa Sawit 10 tahun adalah $\mathrm{Sf}=0,070 \mathrm{Pg}-0,095$ dan $\mathrm{R}^{2} \quad=0,155$ dan yang 20 tahun $\mathrm{Sf}=0,016 \mathrm{Pg}-0,130$ dan $\mathrm{R}^{2}=0,133$.

\section{SARAN}

Untuk keakuratan pengukuran hasil penelitian di lapangan hendaknya digunakan metode event based yaitu pencatatan dilakukan berdasarkan kejadian pada saat terjadinya hujan.

1. Perlu dilakukan penelitian lanjutan untuk mendapatkan data yang lebih baik tentang intersepsi hujan pada perkebunan kelapa sawit dan dengan kemiringan tertentu. 
2. Dalam melakukan penelitian intersepsi disarankan menggunakan kapasitas penampungan air lolos yang lebih besar, sehingga hujan yang tertampung lebih menyeluruh.

\section{DAFTAR KEPUSTAKAAN}

Asdak, C., 2010, Hidrologi dan Pengelolaan DAS, Gadjah Mada University Press,Yogyakarta.

Anonim, 1986, Hidrologi dan Pengelohan Daerah Aliran Sungai, Direktorat Jenderal Pengairan, Badan Penerbit Departemen Pekerjaan Umum, Jakarta.

Benara, R., 2011, Studi Pengaruh Intersepsi Hujan Oleh Perkebunan Kopi $\quad$ Arabika Terhadap Pengelolaan DAS Paya Bener (Studi kasus kebutuhan air minum kota Takengon), Magister Teknik Sipil Unsyiah, Banda Aceh.

Bruijnzeel, LA 1990, Hydrology of Moist Tropical Forests and Effects of Conversion: a State of Knowledge Review. Humid Tropics Programme, IHP-UNESCO, Paris, and Vrije Universiteit,Amsterdam, 224 pp.

Chairani dan jayanti.,2013, Studi Intersepsi Curah Hujan Pada Tegakan Pinus, Jurnal Teknik Pertanian, Fakultas Pertaniaan, Universitas Syiah Kuala, Darusalam, Banda Aceh.

Cameron, JL 2007, Influence of Crown Traits and Leaf Arrangement on Rainfall Interception, Throughfall, and Stemflow in Five Tropical Tree Species, The University of Winnipeg.

Fauzi, Y, Widyastuti, YE, Wibawa, IS dan Hartono, R 2002, Kelapa Sawit : Budidaya, Pemanfaatan Hasil dan Limbah, Analisis Usaha dan Pemasaran. Penebar Swadaya, Jakarta.

Pelawi,S.F., 2009, Studi Intersepsi Pada Berbagai Kelas Umur Tegakan Kelapa Sawit, Kribsi, Progaram Studi Pertanian, Universitas Sumatra Utara, Medan.

Ridwan,B,M., 2009, Penerapan Model Gash Untuk Pendugaan Intersepsi Hujan Pada Perkebunan Kelapa Sawit, Skribsi, Program Sudi Fakultas Pertanian, Instituk Pertaniaan Bogor, Bogor.

Seyhan,E.,1990.Dasar-Dasar Hidrologi. Gadjah MadaTriatmodjo, B.,(2009), Hidrologi Terapan, Beta Offset, Yogyakarta, viewed januari 2015, Available from internet.

http://searches.viview.com/search/web?type $=d s \&$ channel $=w p c \& q=$ triatmodjo

Ward, RC and Robinson, M 1990, Principle of Hidrology, McGraw- Hill, New York.

Yahya, S 1990, Budidaya Kelapa Sawit (Elaeis guineensis Jacq), Fakultas Pertanian, Institut Pertanian Bogor, Bogor. 